\title{
Numerical Modelling of Passively Loaded Pile Groups
}

\author{
Ihsan Al-abboodi (D) Tahsin Toma Sabbagh
}

Received: 7 November 2017/Accepted: 15 December 2018/Published online: 5 January 2019

(C) The Author(s) 2019

\begin{abstract}
Piled foundations could be affected negatively as a result of passive loadings caused by nearby soil movement-induced activities, and failure of piles could happen in some sever cases. This paper deals with the numerical analysis of passively loaded pile groups and piled raft in sand. The complexity involved in such problems due to pile-soil, pile-pile, pile-cap, soil-cap, and moving soil-stable soil interaction needs a powerful tool to make three dimensional analysis possible. In the current study, PLAXIS 3D software was used to back analyse laboratory tests carried out by the authors. "Embedded pile" feature in which the pile is represented by beam elements, while soil-pile interaction along the pile shaft and at the pile tip is described by special interface elements was employed. The Mohr-Coulomb elastic-plastic constitutive model was used to describe the sand behaviour. Although an overestimation of the predicted deflection was obtained, the general trend of bending moment profiles of piles was in a reasonable agreement with those obtained experimentally. A number of limitations were identified as possible reasons behind the
\end{abstract}

I. Al-abboodi ( $\square)$

Department of Civil Engineering, University of Basrah,

Basrah, Iraq

e-mail: i.q.alabboodi@edu.salford.ac.uk

Present Address:

T. T. Sabbagh

School of Computing, Science and Engineering, University of

Salford, Manchester, UK overestimation of the predicted deflections. Furthermore, parametric studies are adopted to consider the effects of pile diameter, pile-soil stiffness and pile group configuration on the response of passively loaded pile groups.

Keywords Pile group $\cdot$ Passive loading $\cdot$ Pile-soil interaction - Soil movements · PLAXIS · Model tests

\section{Introduction}

The negative effects of soil movement-induced activities on human life, economics and environment are of considerable threat, and a lot of researches were made to prevent or reduce the damage impact associated with soil movements (Galli and di Prisco 2012). Typical examples of soil movement-induced activities may include natural phenomena as in cases of unstable soil layers and soil liquefaction, or human activities such as excavations, surcharge loads, tunnelling and pile driving operations. Field investigations showed that soil movement distributions may take several shapes depending on the soil type and the activity. In most cases, these movements take rectangular or triangular profiles. To be distinguished from the active piles which undergoing lateral loads at the pile head level, piles subjected to this kind of lateral ground movements are known as passive piles. 
Researchers developed theoretical and numerical methods range from simple empirical equations to complex three dimensional analysis to study passive piles. Simple problems may involve soil-pile interaction when a single pile subjects to lateral soil movements. In order to shed a light on the response of such piles and to clarify the influence of various parameters, this topic has been analytically studied by several researchers, e.g. (Pan et al. 2002; Miao et al. 2006; Feng et al. 2010; Ghee and Gou 2011; Li et al. 2014; Ekici and Huvaj 2014; Madhumathi and Ilamparuthi 2018). Furthermore, a number of theoretical and empirical methods were developed mainly to estimate the lateral pressure on single piles, e.g. (De Beer and Wallays 1972; Ito and Matsui 1975; Viggiani 1981). Due to the interaction effect of soil, piles and pile cap parameters which could result in an unexpected behaviour of pile groups, analytical studies carried out on single isolated piles might not be appropriate to adopt for pile groups. Complex problems including multi-layer soil, pile groups and soilpile-cap interaction were investigated using numerical methods such as finite elements and finite difference methods, e.g. ( $\mathrm{Ng}$ and Zhang 2001; Ellis and Springman 2001; Chaudhuri 2005; Martin and Chen 2005; Kok and Huat 2008; Sawant and Shukla 2012; He et al. 2015; Hirai 2016; Nguyen et al. 2016; Nishanthan et al. 2017). A broad variety of parameters have been studied using various computer softwares such as PLAXIS, FLAC3D, ANSYS and ABAQUS. Although PLAXIS 3D has been widely used to investigate the response of pile foundations under various loading conditions, a limited information is available concerning the ability of "embedded pile" feature, in which the pile is represented by beam elements surrounded by special interface elements, to simulate the response of passively loaded pile groups.

In this study, a series of runs were carried out utilising the "embedded pile" feature provided by PLAXIS 3D software aimed to investigate the response of capped-head passively loaded pile groups under uniform and triangular soil movement profiles. Furthermore, parametric studies were conducted to figure out the influence of pile diameter, pile-soil stiffness and pile group arrangement on the behaviour of pile groups subjected to uniform soil movements.

\section{Numerical Analysis}

\subsection{Embedded Pile}

The embedded pile is a special feature in PLAXIS 3D which was developed to simulate the behaviour of piles in a simplified way. In this approach, the pile is represented by beam elements, while soil-pile interaction along the pile shaft and at the pile tip is described by special interface elements. The generation of linear beam elements gives the opportunity to simulate piles as structural elements with specified material properties (Brinkgreve et al. 2010). Comparing the analytical results of embedded pile with that obtained by using volume pile in modelling a laterally loaded pile response showed a good agreement between them (Dao 2011). Furthermore, a practical axially loaded pile behaviour was simulated efficiently by using an embedded pile feature (Sluis et al. 2013; Sheil and Mccabe 2012). It is important to mention that the calculation time and the number of elements required to analyse a certain pile-soil interaction problem are sufficiently reduced by using embedded piles compared to using volume piles. Another advantage of the embedded pile is that the output forces can be directly obtained, unlike the volume pile which is modelled as soil material. However, one of the limitations of the embedded pile is that it does not take the method of installation into account. Therefore, driven and displacement piles could be affected more than bored and augered piles due to this limitation (Haryono 2013).

\subsection{Pile-Soil Interaction}

The interaction is governed by the skin resistance along the pile shaft and the foot resistance, which their sum gives the total bearing capacity of the pile. The values of skin and base resistances are considered as input data, and can be calculated theoretically or from pile load test results.

In order to control the strength properties of the interface, PLAXIS provides "interface strength reduction factor, $R_{\text {int }}$ ", which can be used to reduce the shear resistance (skin resistance) of the interface allowing a "slide" to occur between the pile and soil nodes. In other words, relative displacement, which is one of the important factors affecting the response of passive piles, can occur between the pile and the soil. 
In fact, relative displacement is only allowed in the axial direction of the pile. However, the assumed elastic behaviour of the pile in the lateral direction leads the pile displacement to coincide with the soil displacement, i.e. no slide of the soil can develop at pile skin. Thus, the nature of pile surface (rough or smooth) could play an essential rule in the performance of laterally loaded piles simulated by embedded pile feature. However, it is not clear whether the embedded pile is suitable for modelling the response of "smooth" piles subjected to lateral soil movement, which is the main objective of this study.

\subsection{Validation of Model Tests}

A series of model tests were carried out on a $2 \times 2$ free-standing pile group. In the current study, only two experimental tests were performed for comparison, namely PG1 and PG2 subjected to uniform and triangular soil movements profiles respectively. The experimental apparatus and testing procedure are briefly described here and more details can be found in (Al-abboodi and Sabbagh 2017). The testing box and loading system are presented in Fig. 1. The shear box had internal dimensions of $0.6 \times 0.6 \mathrm{~m}$, and $0.69 \mathrm{~m}$ in height. The total height of the box was divided into $0.5 \mathrm{~m}$ stationary box and $0.19 \mathrm{~m}$ laminar movable frames. The shape of the lateral soil movement profile and the moving depth $\left(L_{m}\right)$ were controlled by loading blocks attached to the lateral loading system. Capped-head and free-tip aluminium piles were used with a $3 D$ pile spacing ( $D$ is the pile diameter). Two piles (one at each row) were instrumented with strain gauges to measure bending moments and other responses along the pile length.

\subsubsection{Soil Properties}

The pile groups were tested in a dry sand with a unit weight of $16.0 \mathrm{kN} / \mathrm{m}^{3}$ (relative density $=80 \%$ ), friction angle $(\varphi)$ of $39^{\circ}$ and Poisson's ratio of 0.3 . The dilation angle $(\psi)$ was input as $9^{\circ}$. This value was calculated according to the equation $\psi=\varphi-30$. The Young's modulus of the sand at the mid-depth of the testing box was estimated according to relations suggested by Poulos (1989) as 1.2 MPa. A value of cohesion, $c=1.0 \mathrm{kPa}$ was adopted for sand. A MohrCoulomb elastic-plastic constitutive model was assumed for the soil. Pouring and tamping method were used to achieve a reasonably constant density of the sand in the testing box.

\subsubsection{Piles and Pile Cap Properties}

The tests were performed on aluminium tubes having a length of $300 \mathrm{~mm}$, an outer diameter of $19.0 \mathrm{~mm}$ and a wall thickness of $1.0 \mathrm{~mm}$. To provide a frictional protection to the strain gauges during driving and testing processes, piles were covered with a special adhesive tape. Thus, the final outer diameter of piles was approximately (20) $\mathrm{mm}$. The internal friction angle between the sand and the adhesive tape was

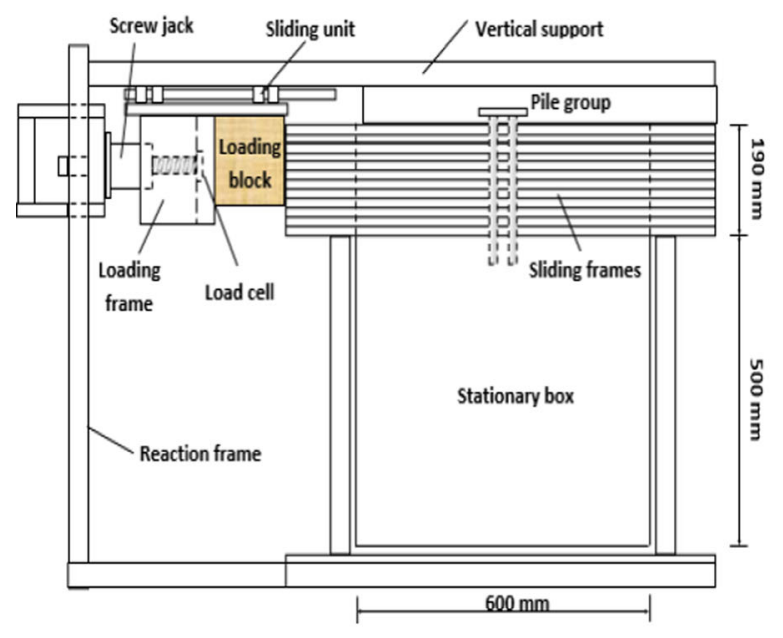

a. Elevation view

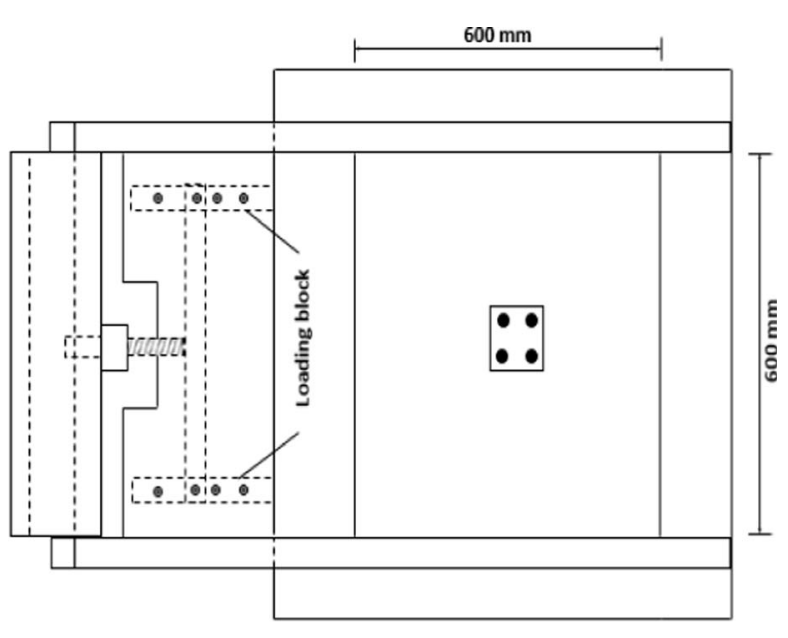

b. Plan view

Fig. 1 Experimental apparatus showing testing box and loading frame 
found to be $20^{\circ}$. The tests were conducted on a freestanding pile group with a gap of $15 \mathrm{~mm}$ was left between the soil surface and the pile cap. Aluminium plates were used to fabricate pile caps with dimensions of $0.1 \times 0.1 \mathrm{~m}$, and $9 \mathrm{~mm}$ in thickness. All piles and pile cap had a Young's modulus of $70 \times 10^{6} \mathrm{kN} / \mathrm{m}^{2}$. A vertical jacking load was used to derive the pile group into the soil.

\subsubsection{Boundary Conditions}

Inevitably, a proper representation of boundary conditions is vital in the analysis of passive piles. For the back analysis of model test, a uniform or triangular prescribed lateral soil movements were applied to the left and right boundaries (surfaces ABCD and EFGH in Fig. 2). Those boundaries were, also, unrestrained in the $\mathrm{Y}$ and $\mathrm{Z}$ directions. The faces parallel to the $\mathrm{X}-\mathrm{Z}$ plane (ACGE and BDHF) were restrained from moving in the Y-direction. The top surface (AEFB) was free to move in any direction.

Theoretically, soil strength could reduce with the development of soil movement (Martin and Chen 2005). The reduced strength is known as residual strength and it can be clearly observed in the direct shear test of sand. Therefore, an interface surface with reduced strength was added between the sliding and stable soil layers (surface CGHD).

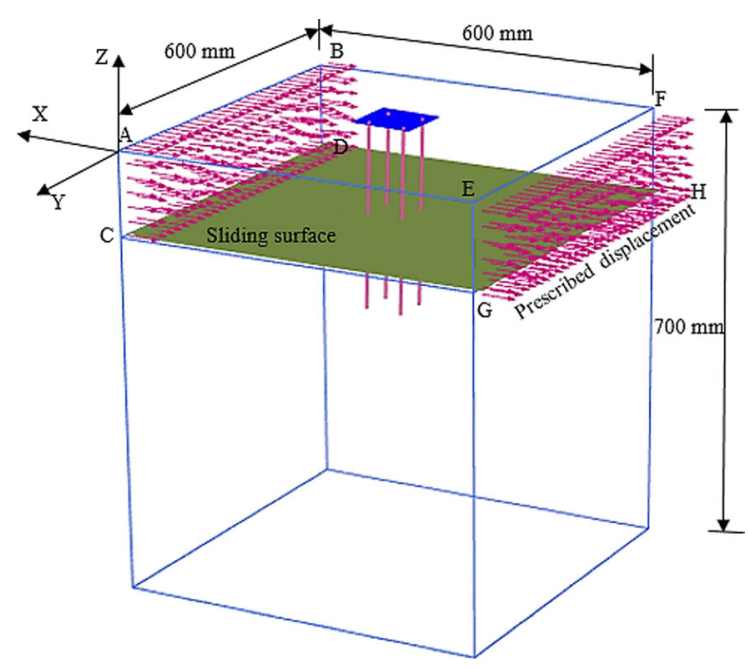

Fig. 2 3-D view and boundary conditions

\subsubsection{Strength Reduction Factor $\left(R_{\text {int }}\right)$ for the Sliding Surface}

In general, one of the keys to a realistic analytical solution of passively loaded piles lies in the determination of proper strength properties for the sliding surface. In this context, researchers either add a virtual weak soil between the sliding and stable soil layers or introduce an interface surface with reduced strength (see for example, Jeong et al. 2003; Kahyaoglu et al. 2009; Kanagasabai 2010; Kourkoulis et al. 2011). In the current study, the concept of interface surface with strength reduction factor $\left(R_{\text {int }}\right)$ was adopted. A number of analytical runs have been carried out to choose a proper value for this parameter. At each run, the analytical results were compared with two experimental observations obtained from a special laboratory test (known as soil deformation test) employed for this purpose. The first observation is the deformation shape of the top soil surface after conducting the test. In particular, the large settlement of the sand at the far end (the right hand side boundary) which was observed at the end of the test. The second observation is the soil movement profiles at three locations within the testing box measured from soil surface down to a depth of $300 \mathrm{~mm}$.

In the soil deformation test, soil properties and sliding depth $\left(L_{m}\right)$ were similar to the model test with uniform movement profile but without piles (soil only). In order to investigate the sand movement profile within the depth of sand layer, light weight plastic beads were placed at predetermined depths and three sections within the testing box. The distances of sections with respect to the left-hand inner face of the testing box $\left(L_{b}\right)$ were 150,300 and $450 \mathrm{~mm}$ respectively. The light weight of the beads helped to follow the sand movement. The beads were $5 \mathrm{~mm}$ in diameter connected together by a nylon thread forming a chain. The vertical distance between adjacent beads was $10 \mathrm{~mm}$. The thread was extended and connected to the base of the testing box, while the top end was tied to a horizontal beam. The beam was also used as a guide to measure the displacements of beads after the test. A spirit level was used to ensure the vertical alignment of the bead chains in their initial locations.

After furnishing soil layers, the thread was cut from its top end to free the bead chain. The test was carried out with a maximum of $30 \mathrm{~mm}$ of box displacement $\left(\Delta_{B}\right)$. Once the test was completed, the sand was 
removed carefully, and the new locations of the plastic beads were measured. By examining beads locations before and after the test, the lateral soil movement profile can be drawn.

\section{Results}

\subsection{Analysis Results of Soil Movement Profile}

Analysis results showed that, when $R_{\text {int }}=0.5$, the soil was moved as one mass in which all sand particles had the same displacement with no heaving or settlement at any part of the testing box. In fact, this kind of behaviour was observed for any value of $R_{\text {int }}$ lies between 0 and 0.81 . Also, the analytical results of sand with $R_{\text {int }}=1.0$ (no interface) did not represent the two above mentioned governed observations properly. Although lateral deformations at the left and right boundaries were in a good agreement with the observed deformations, the centre of the box has recorded less lateral deformations than that obtained by beads measurements. Furthermore, sand heave at the left boundary was overestimated.

After several trials, it was found that the value of $\left(R_{\text {int }}=0.95\right)$ gives a reasonable simulation of the measured sand deformations. Figure 3 compares the experimental (beads measurements) and analytical results (using $R_{\text {int }}=0.95$ ) of the lateral soil movement distributions at the three sections. Despite some differences at (and close to) the sliding surface, it can be clearly seen that numerical results are in good agreement with the experimental measurements at the three sections.

\subsection{Analysis Results of Test PG1}

The accuracy of the proposed numerical procedure is checked by comparing the predicted results with those obtained from an experimental test PG1. In this test, a uniform soil movement profile was used starting from the soil surface down to a depth of $135 \mathrm{~mm}\left(L_{m}\right.$ $=135 \mathrm{~mm}$ ). The comparison was made in terms of bending moment, shear force and deflection profiles for the front and back piles. The terms "front" and "back" pile are used to describe the pile in terms of its location to the source of lateral loading. Hence, a front pile (pile F) refers to the one which is nearest to the source of lateral loading and influenced by the soil displacements before a back pile (pile B). Further investigation of the predicted soil deformations resulted after displacing the upper moving soil layer a lateral distance $\left(\Delta_{B}\right)$ of $30 \mathrm{~mm}$ is also conducted (Fig. 4).

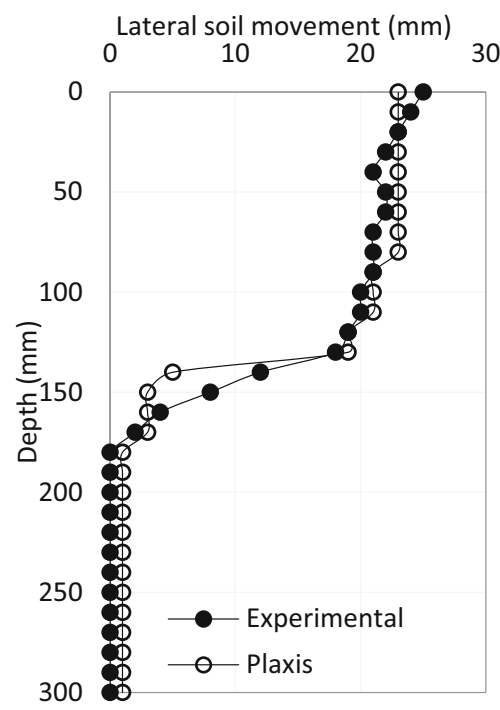

a. $L_{b}=150 \mathrm{~mm}$

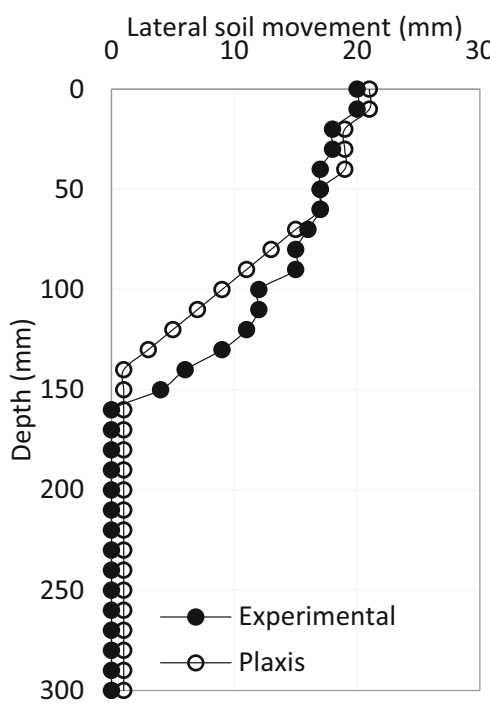

b. $L_{b}=300 \mathrm{~mm}$

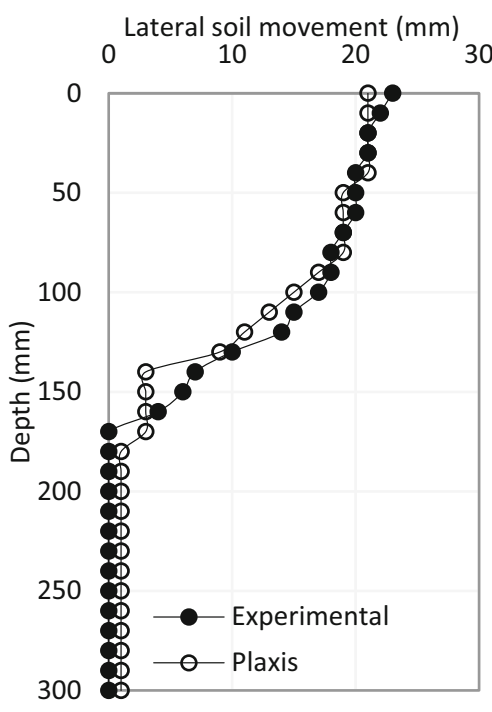

c. $L_{b}=450 \mathrm{~mm}$

Fig. 3 A comparison between experimental and analytical lateral soil movement distribution at three sections of the box at $\Delta_{B}=30 \mathrm{~mm}$ 


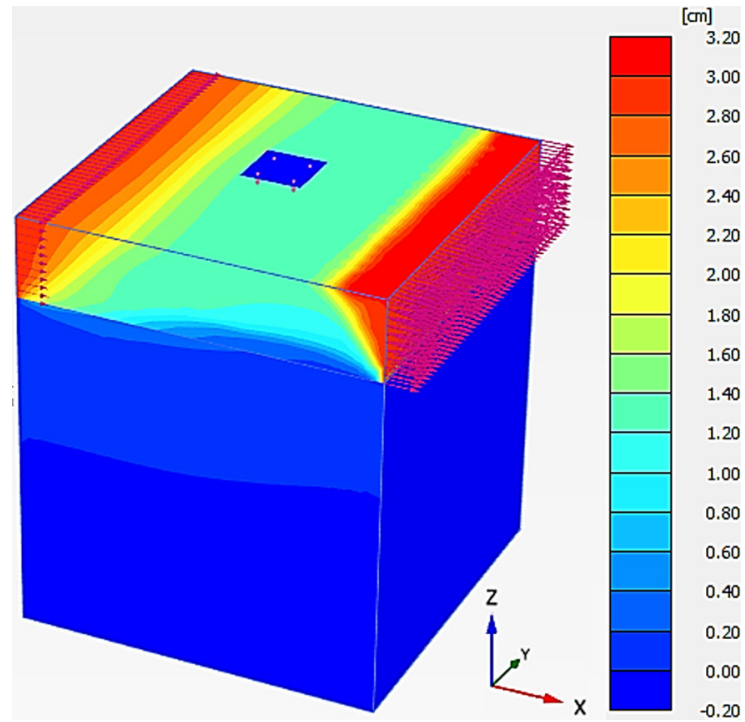

Fig. 4 Lateral deformations at $\Delta_{B}=30 \mathrm{~mm}$

As expected, comparing the lateral deformations in Fig. 4 with that obtained in the case of no piles (soil only) in Fig. 3 shows the restriction of soil movements occurs when providing piles, which is the main concept of soil stabilisation piles. This finding illustrates one of the drawbacks of the displacement-based method used to analyse passive piles. Based on this method, the estimated or measured free-field soil displacement in the absence of piles is obtained first and then applied directly to the piles (Poulos 1973; Lee et al. 1995). In fact, the response of passive piles depends mainly on the soil movement profile which is, in turn, affected by the existence of piles.

Lateral deformations of soil at three horizontal sections $(z=10,70$ and $135 \mathrm{~mm})$ under the soil surface at $\Delta_{B}=30 \mathrm{~mm}$ is presented in Fig. 5. It appeared that the restriction of soil movement and lateral soil arching, which is defined as the formation of different soil displacements in a horizontal plane (Wang et al. 2013) were increased with increasing pile depth.

Figure 6 compares the experimental and the analytical responses in terms of moment, shear and deflection of the front and back piles at $\Delta_{B}=30 \mathrm{~mm}$. The general trend of the three predicted profiles deduced analytically were in good agreement with those obtained from the model tests. The positions of maximum and minimum bending moments for the front and back piles were estimated successively.
However, with the exception of pile head moment, analytical results were underestimated the bending moment of the front pile. For the back pile, Fig. $6 \mathrm{~d}$ shows that the predicted pile head moment was $10 \%$ less than the experimental value. The position of zero bending moment was shifted upward away from the sliding surface. Furthermore, although the location of maximum positive moment was estimated correctly, the magnitude from numerical analysis was over predicted by about 2.8 times of that measured by strain gauges.

On the other hand, shear force distributions of the front and back piles were observed to be well predicted. The upper portions of piles were showed the more similar behaviour. However, analytical results of shear force were, generally, noticed to be overestimated compared to shear force values obtained by differentiating the bending moment profile along the pile depth to the 1 st order. The difference was in its maximum at the sliding surface and pile tip. Figure $6 \mathrm{~b}$, e shows $27 \%$ and $6 \%$ difference in the pile head shear force, while the difference was $370 \%$ and $120 \%$ at the sliding surface for the front and back pile respectively. Furthermore, unrealistic values of shear force were obtained at the pile tip.

Figure $6 \mathrm{c}, \mathrm{f}$ portrays the lateral deformations of piles achieved from model tests and numerical analysis. Although both cases have resulted in a rigid response of piles with rotation points closed to the pile tip, the comparison highlights the clear increase in the predicted deformations. Interestingly, pile head displacement is significantly more than the measured data by about $90 \%$. The failure in capturing the real deformation of smooth piles can be attributed to the absence of the concept of relative displacement between the pile and the surrounding soil involved in "embedded pile". Therefore, the upper portions of piles were almost displaced laterally a similar value of the lateral displacement of the surrounding soil as if they were bonded together. This caused the lateral deformation of piles to be overestimated. Moreover, the change in sand density after the instillation of pile group is not taken into account and can not be simulated using "embedded pile". 


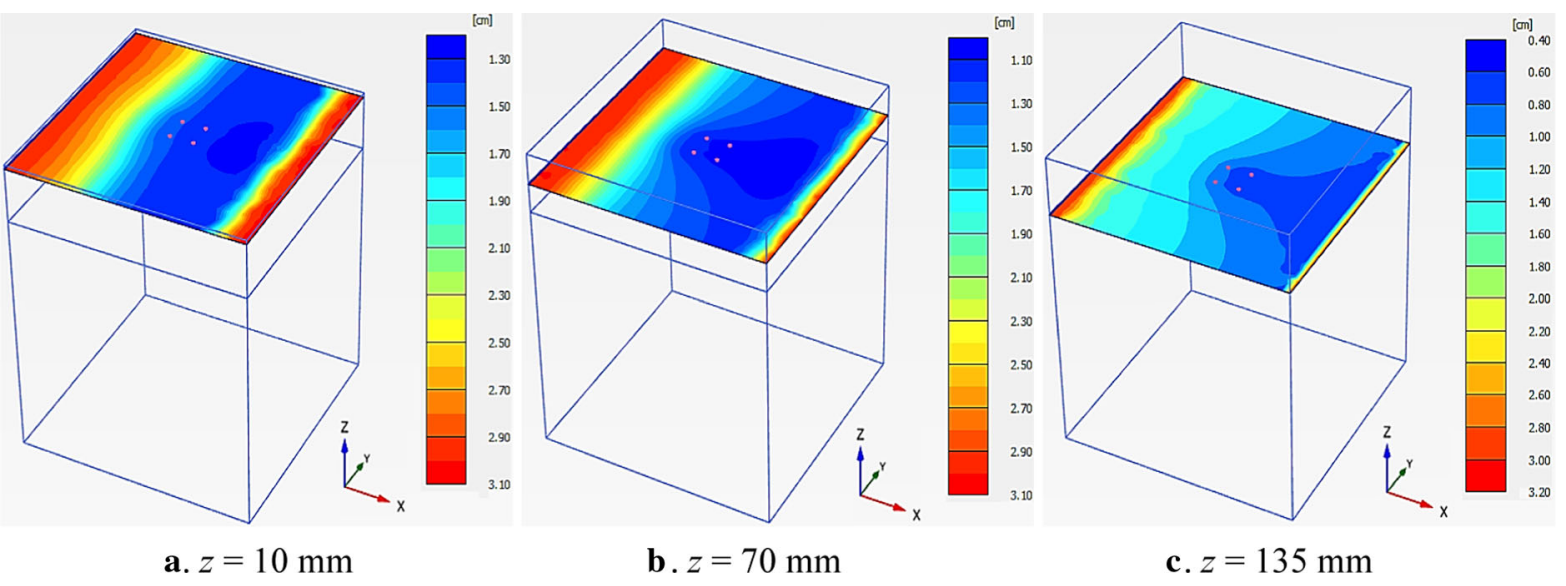

Fig. 5 Lateral deformation of soil at three horizontal cross sections at $\Delta_{B}=30 \mathrm{~mm}$

\subsection{Analysis Results of Test PG2}

A similar back analysis of model test PG1 was carried out, but with a triangular soil movement profile at the boundaries with a maximum soil displacement of $20 \mathrm{~mm}$ at soil surface and 0 displacement at a depth of $135 \mathrm{~mm}$ under the soil surface. Due to the nature of triangular profile, no interface elements were added at that depth. Soil and pile properties were similar to those used for test PG1.

Vertical and lateral soil deformations obtained at $\Delta_{B T}=20 \mathrm{~mm}$ are illustrated in Fig. 7 (note that $\Delta_{B T}$ here refers to the lateral movement applied at the soil surface through triangular soil profile). It can be seen that the majority of vertical deformations were concentrated at the box boundaries. This behaviour is similar to what has been observed during the laboratory test.

Figure 8 shows the predicted results with the corresponding model test results, focusing on bending moments, shear forces and lateral deflections of piles. It can be seen that the predicted and measured bending moment profiles are similar (Fig. 8a, d). The double curvature of moment distribution in the front pile was predicted successively. Although the positions of maximum positive and negative moments were shifted slightly upward, the maximum values were nearly the same. The similarity was more pronounced when comparing the pile head moments for both piles. However, the analytical maximum positive moment of the back pile was over estimated by about 3 fold of that measured experimentally.
The shape of shear force distributions of both piles were observed to be well predicted compared to those obtained from model tests (Fig. 8b, e). However, shear force values predicted in the front pile showed a better match with the experimental data compared to those deduced in the back pile. The latter recorded a difference of $85 \%$ between the two cases in the pile head shear force, while the difference was only $10 \%$ in the front pile.

As expected, an overestimation of the lateral deflection in piles is noted again. Figure $8 \mathrm{c}$, $\mathrm{f}$ shows that the maximum deflection (located at the pile head) computed analytically is more than the experimental value by about 3 fold.

In general, the analytical results of test PG2 were noticed to be more similar to the experimental data compared to those obtained in test PG1. One of the reasons for the good prediction of the results of this test could be the lack of the sliding surface interface. This means a better prediction of soil movement profile could be achieved.

\section{Parametric Studies}

Parametric studies were conducted numerically to examine the influence of various pile parameters on the performance of passively loaded pile groups. In order the results to be comparable, soil, pile and cap properties were similar to those used in the back analysis of test PG1 unless stated otherwise. The effects of pile diameter, pile-soil relative stiffness and pile group configuration were studied. 


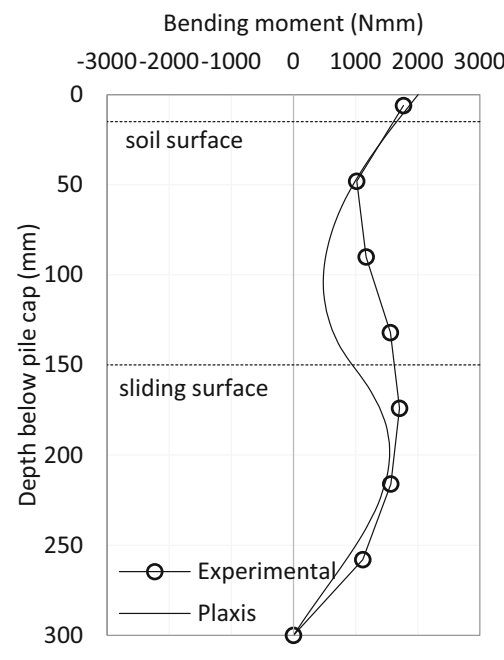

a. Bending moment, pile F

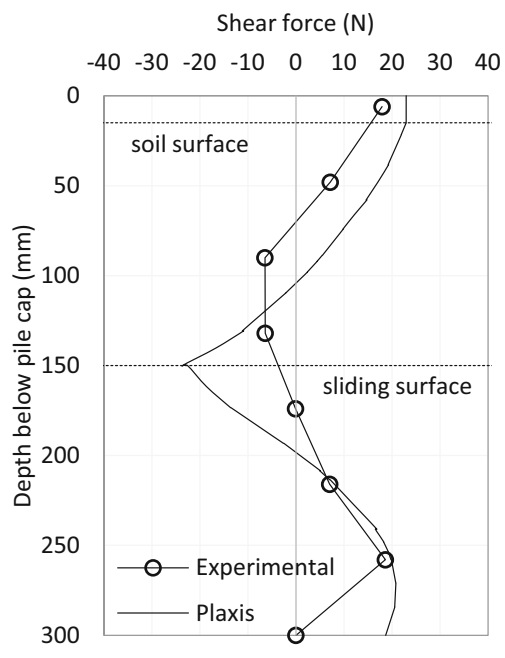

b. Shear force, pile F

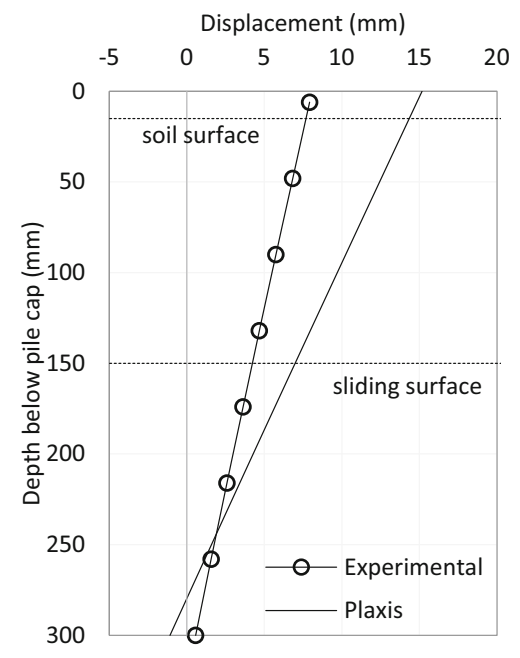

c. Deflection, pile F
Bending moment ( $\mathrm{Nmm})$ $-3000-2000-1000 \quad 0 \quad 100020003000$

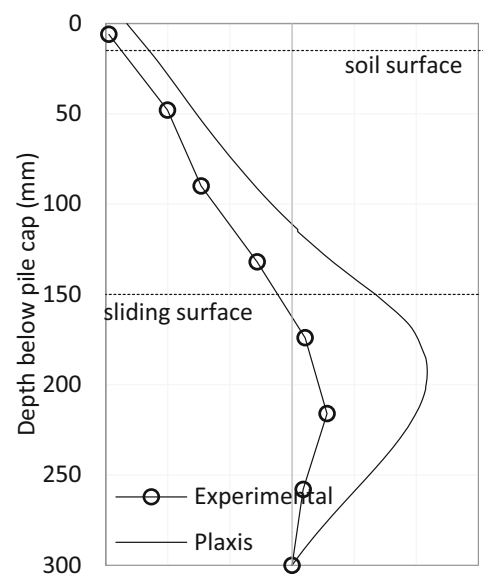

d. Bending moment, pile B

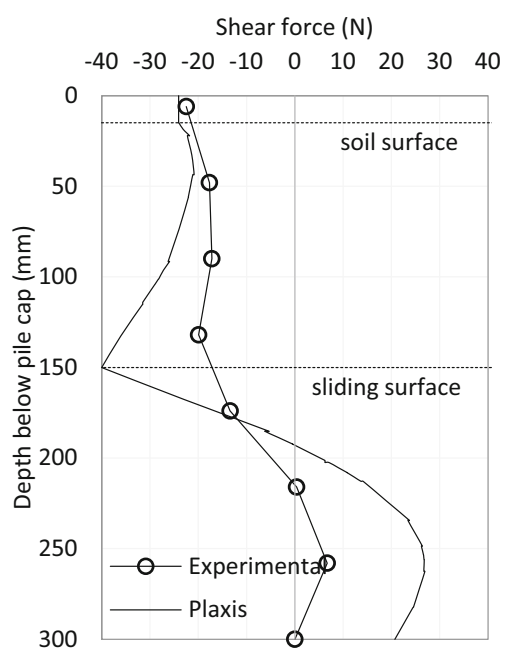

e. Shear force, pile B

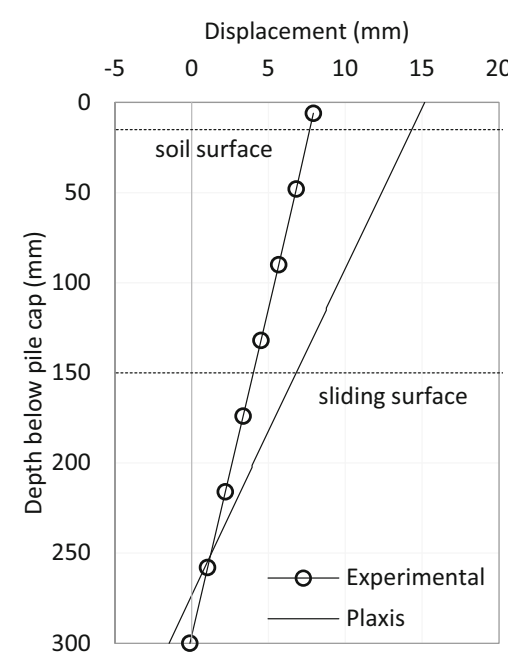

f. Deflection, pile B

Fig. 6 Predicted versus measured piles responses of test PG1 at $\Delta_{B}=30 \mathrm{~mm}$

\subsection{Effect of Pile Diameter $(D)$}

The effect of pile diameter on the response of passively loaded pile group was investigated by considering four different values of pile diameter in the analysis, i.e. 10, 15, 20 and $30 \mathrm{~mm}$. The analysis was done with a $2 \times 2$ free-standing pile group loaded passively with a uniform profile of sand movement at the boundaries up to $\Delta_{B}=30 \mathrm{~mm}$. Pile spacing was kept at $3 D$ for all cases. For the front pile row, Fig. 9a shows that the position of maximum moment for the cases of $D=10$ and $15 \mathrm{~mm}$ was shifted down to the stable soil, unlike other diameters which were recorded maximum moments at pile heads. Pile heads showed an increase in their bending moments as pile diameter increased. This trend can also be observed in the bending moment calculated at the back pile row (Fig. 9b). This response can be attributed to the fact that piles with larger diameters offering more resistance to the soil movements, resulting in a higher load carried by piles which leads, in turn, to increase moments on the piles. However, the rate of bending 


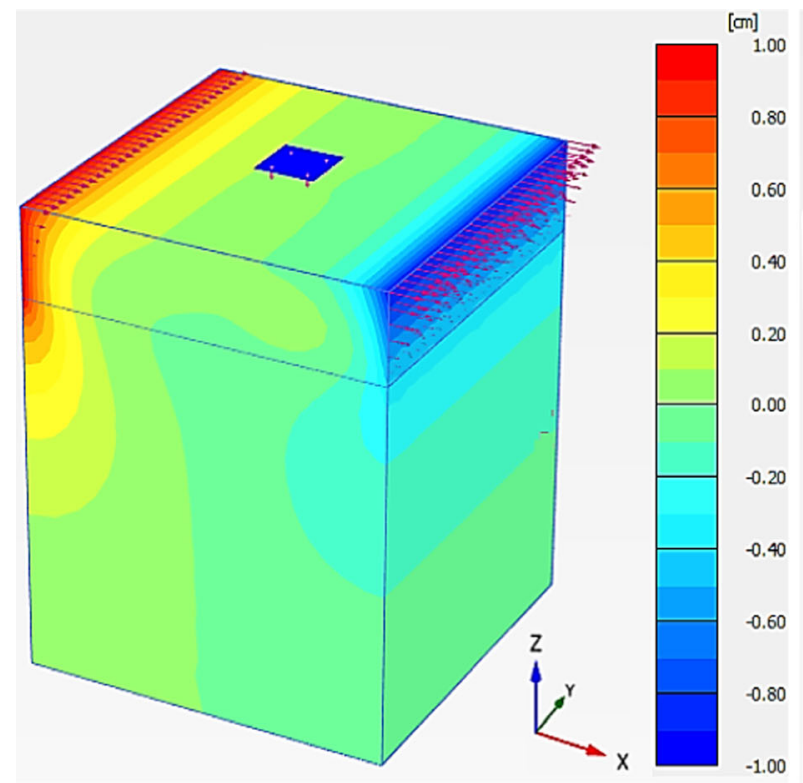

a. Vertical deformations

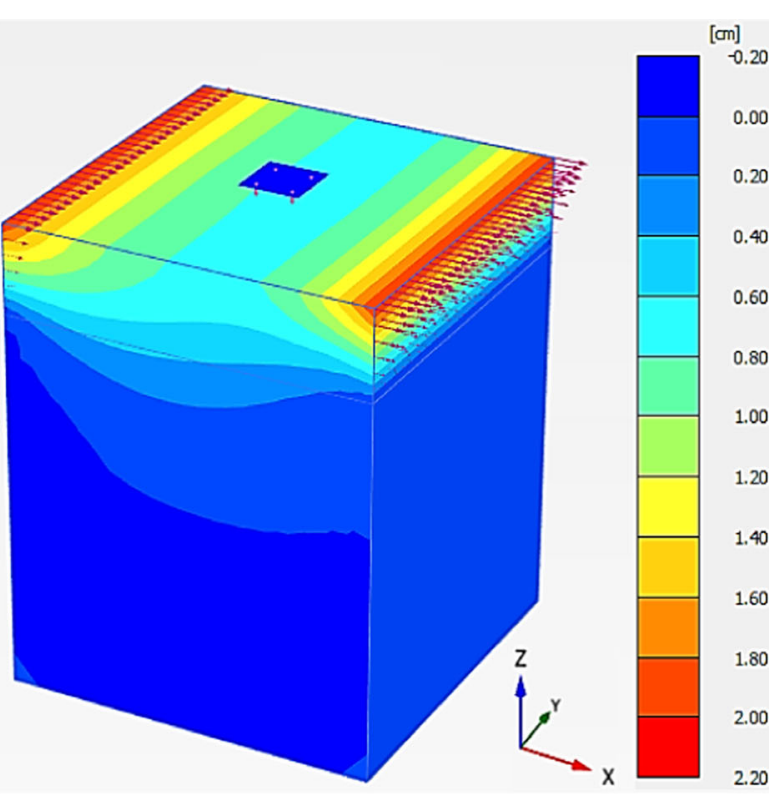

b. Lateral deformations

Fig. 7 Vertical and lateral deformations at $\Delta_{B T}=20 \mathrm{~mm}$

moment increase was decreased when $D$ was increased from 20 to $30 \mathrm{~mm}$.

Lateral displacements showed a dramatic decrease with increasing pile diameter. The results support the assumption of increasing pile resistance to the movement of soil with increasing pile diameter. Figure 9c compares the predicted displacement results of the four values of pile diameters. It can be seen that increasing $D$ from 10 to $30 \mathrm{~mm}$ caused a considerable decrease in pile head displacement by about $30 \%$.

\subsection{Effect of Relative Pile-Soil Stiffness $\left(K_{r}\right)$}

Relative stiffness can be calculated according to the following formula (Poulos and Davis 1980):

$K_{r}=E_{p} I_{p} / E_{s} L_{p}^{4}$

where $E_{p}$ and $I_{p}$ are the modulus of elasticity and moment of inertia of the pile respectively, $E_{s}$ is the average Young's modulus of the soil, and $L_{p}$ is the length of the pile. The piles are considered rigid piles when $K_{r}$ values are greater than 0.01 .

The influence of relative pile-soil stiffness was evaluated by changing the properties of pile material. Two values of $K_{r}$ were considered (0.02 and 0.0004), reflecting both rigid and flexible pile types respectively. Figure 10a, b portrays the differences in response in terms of bending moment under a soil movement of $30 \mathrm{~mm}$ at boundaries. Although the shape of moment profile seems to be similar with a double curvature in the front pile and negative and positive values at the upper and lower parts of the back pile respectively, significant differences in magnitudes can be observed especially over the moving layer. Bending moments calculated at pile heads showed a notable reduction in magnitudes when flexible piles are considered. The reduction was $88 \%$ in the front pile and $73 \%$ in the back pile compared to the rigid pile response. The differences in deflection mode between the two cases can be recognised in Fig. 10c. Although flexible piles have recorded only a slight increase in their head deflections, it can be noted from Fig. 10c that a value of $K_{r}=0.0004$ has resulted in a remarkable change in the bending deformation of piles from a rigid mode to a flexible mode. The calculated pile depth-lateral deformation curves confirm the significant effects of the relative pile-soil stiffness in the response of passive piles. 


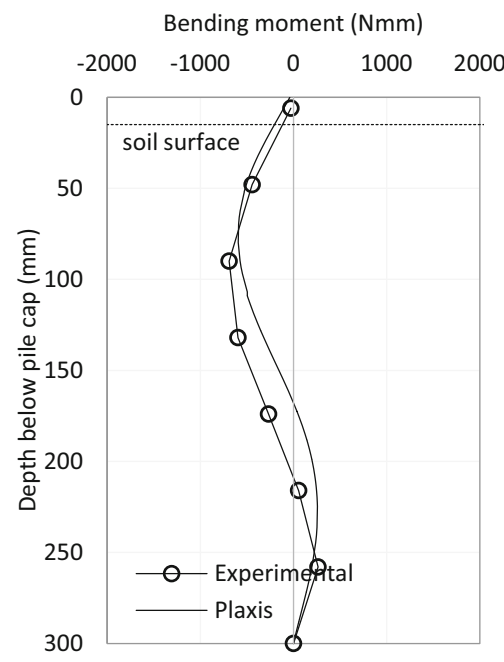

a. Bending moment, pile F

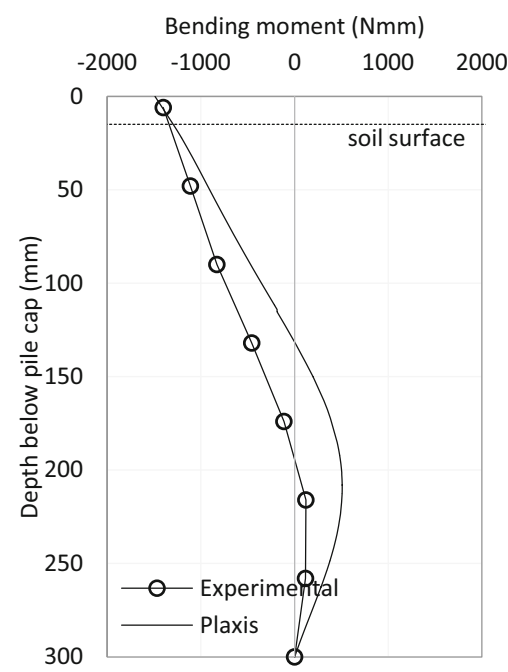

d. Bending moment, pile B

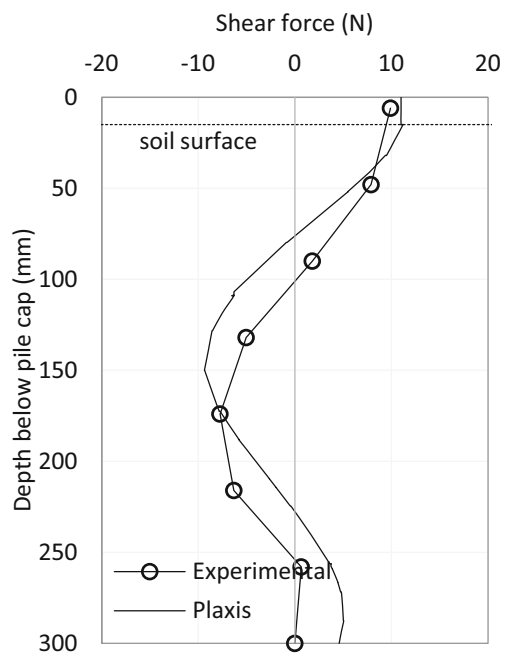

b. Shear force, pile $\mathrm{F}$

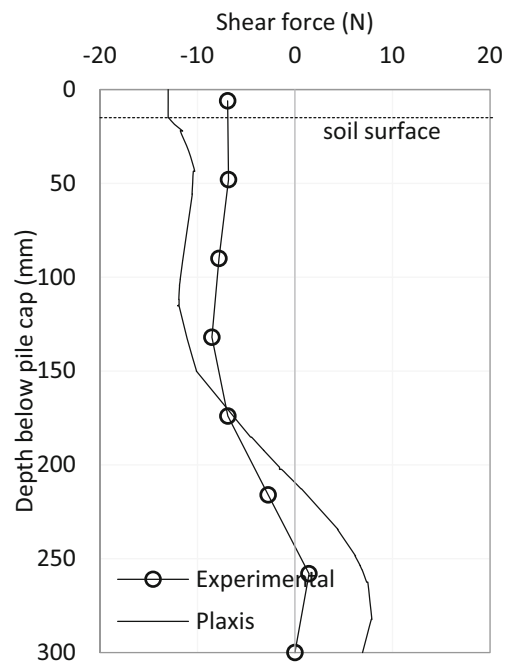

e. Shear force, pile B

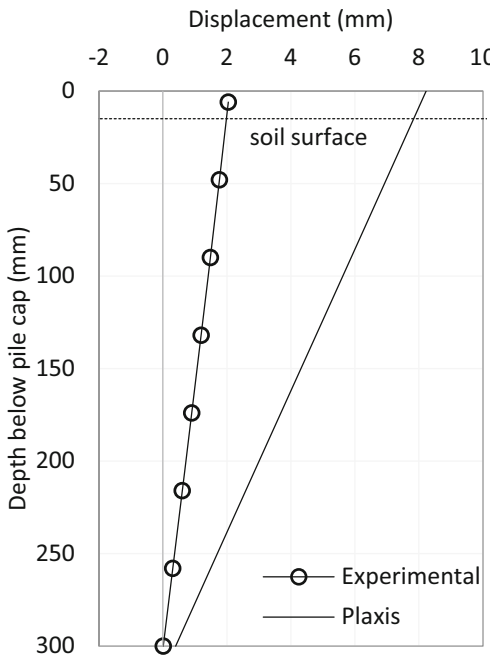

c. Deflection, pile F

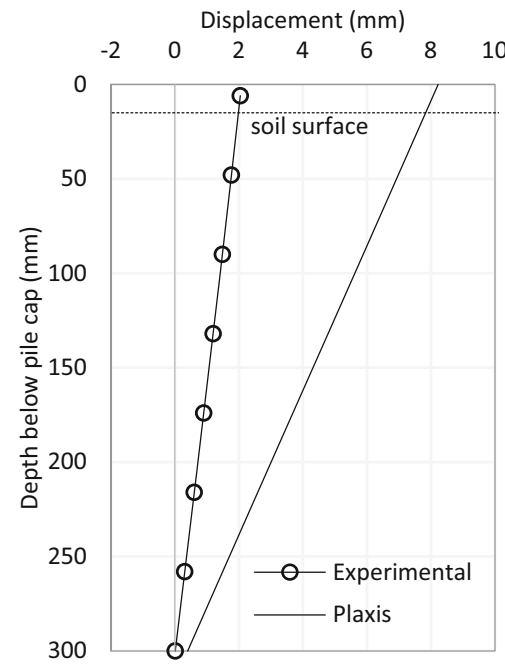

f. Deflection, pile B

Fig. 8 Predicted versus measured piles responses of test PG2 at $\Delta_{B T}=20 \mathrm{~mm}$

\subsection{Effect of Pile Group Configuration}

A series of numerical runs were conducted to clarify the influence of pile arrangement and the number of piles within a group on the behaviour of pile groups subjected to uniform soil movements. The numerical investigation involved various configurations of freestanding pile groups with various number of piles (Fig. 11). The centre to centre spacing of piles were kept at $3 D$ in both directions. According to the arrangement of piles relative to the direction of soil movement, two categories of pile groups were considered. The first category contains $(2 \times 2)$, $(2 \times 3)$ and $(2 \times 4)$ pile groups in which the number of rows was kept at 2 for all pile groups. The orientation of pile groups has been reversed in the second series of arrangements which was included $(3 \times 2)$ and $(4 \times 2)$ in addition to the standard $(2 \times 2)$ pile group. The terms " 2 nd row" and " 3 rd 
Bending moment $(\mathrm{Nmm})$ $-3000-2000-1000 \quad 0 \quad 100020003000$

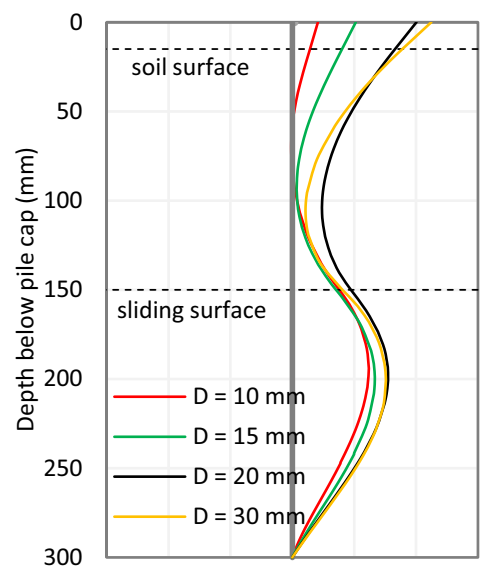

a. Bending moment, pile $\mathrm{F}$
Bending moment ( $\mathrm{Nmm}$ )

$-3000-2000-1000 \quad 0 \quad 100020003000$

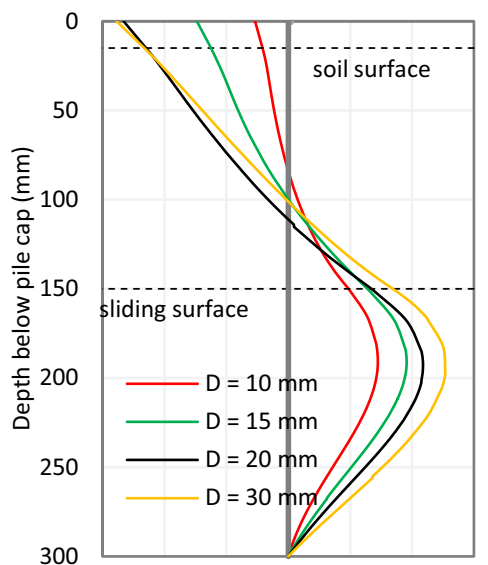

b. Bending moment, pile B

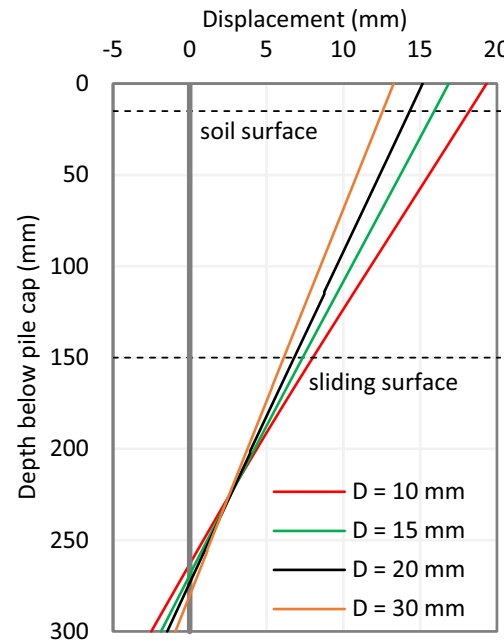

c. Deflection, pile F

Fig. 9 Responses of piles at different values of pile diameter at $\Delta_{B}=30 \mathrm{~mm}$

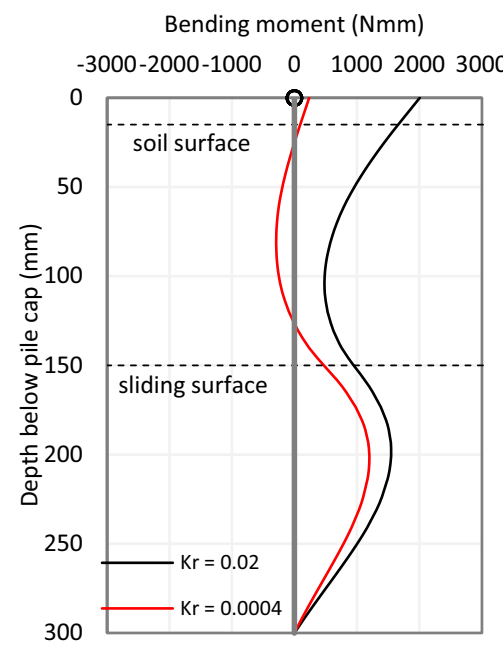

a. Bending moment, pile $\mathrm{F}$

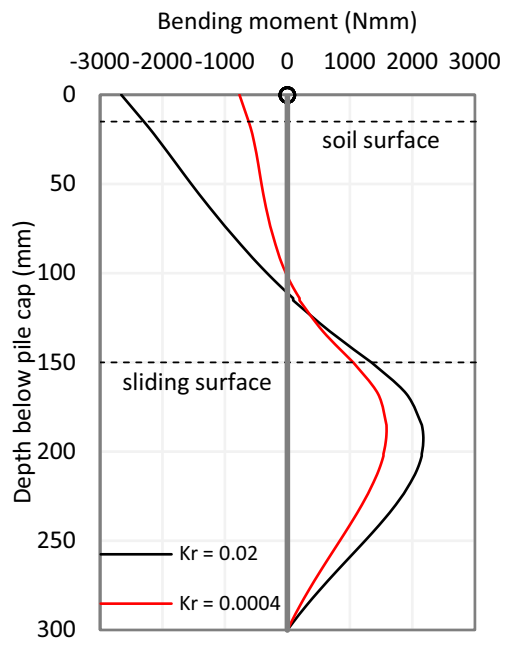

b. Bending moment, pile B

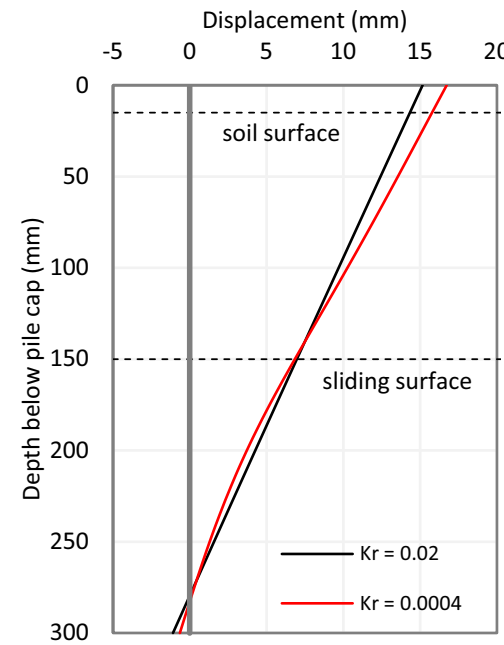

c. Deflection of pile

Fig. 10 Responses of piles at different values of $K_{r}$ at $\Delta_{B}=30 \mathrm{~mm}$

row" are used to describe a pile row position relative to the source of lateral loading.

The comparison in Fig. 12a, b highlights the similarity in the shape of bending moment profiles for both front and back pile rows regardless the number of piles in the group. It is shown that bending moment values of the $(2 \times 2)$ pile group were considerably higher than those in other pile group configurations. The maximum differences were found to be at pile heads, in which bending moments in the front and back pile rows in $(2 \times 2)$ pile group were approximately $65 \%$ higher than those obtained in $(2 \times 3)$ and $(2 \times 4)$ pile groups. Most importantly, Fig. 12a, b reveals that bending moment profiles were influenced only slightly by increasing the number of pile lines parallel to the direction of soil movement beyond 3 lines. It can be seen that responses of the $(2 \times 3)$ and $(2 \times 4)$ pile groups were very similar in shapes and magnitudes. Experimentally, this finding has been also observed by (Chen et al. 1997) in their 
Fig. 11 Pile group configurations used in the analysis

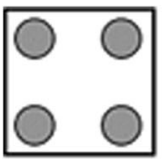

$2 \times 2$

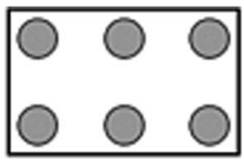

$2 \times 3$

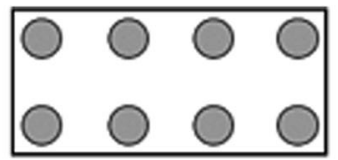

Back row

Front row
$3 \times 2$
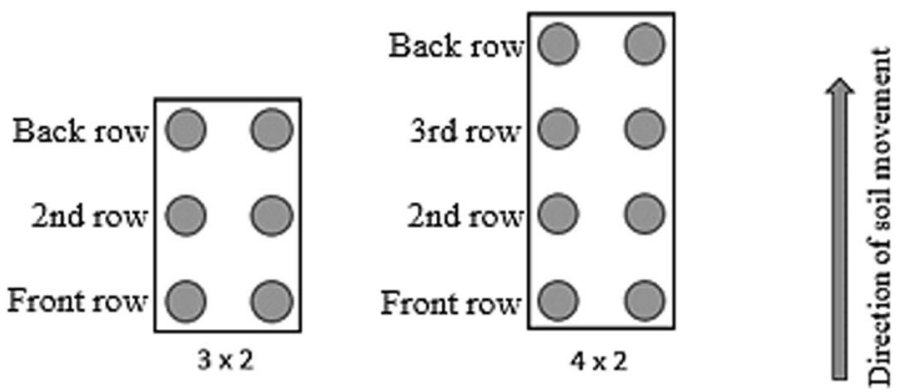

$2 \times 4$

Bending moment (Nmm)

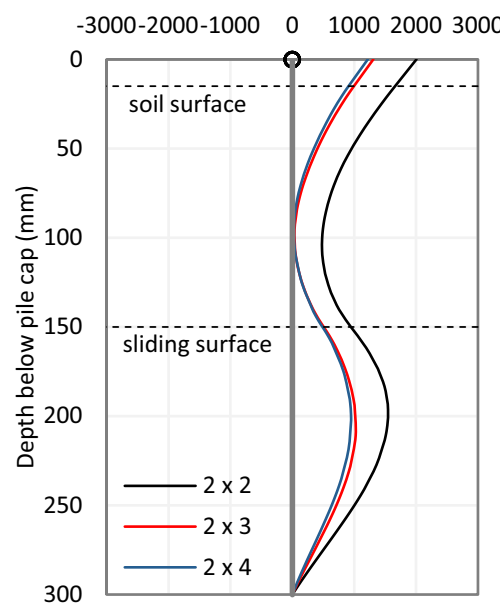

a. Bending moment, pile $\mathrm{F}$

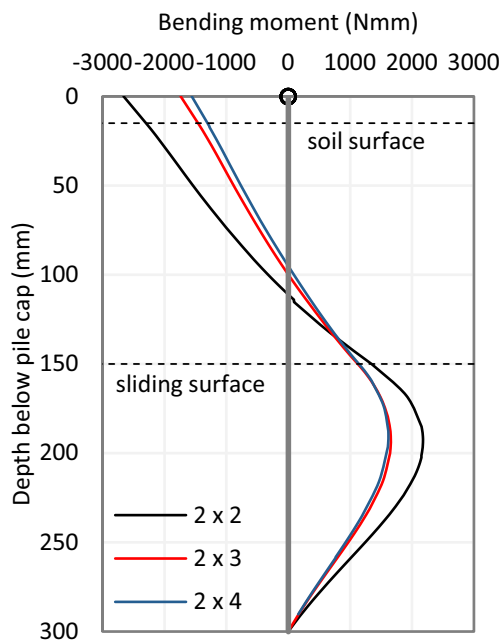

b. Bending moment, pile B

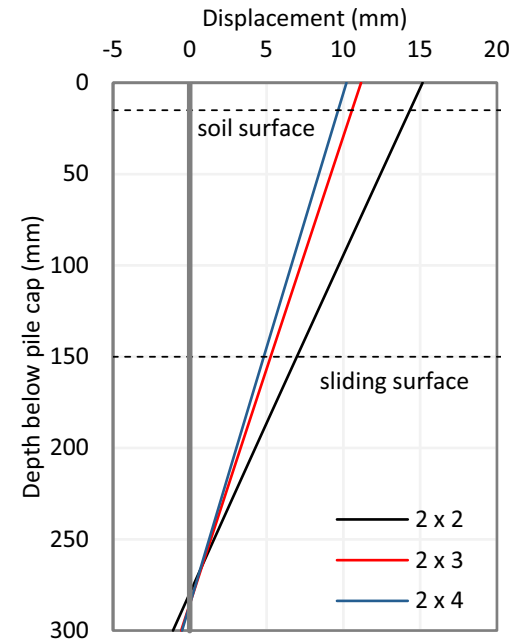

c. Deflection, pile F

Fig. 12 Responses of $(2 \times 2),(2 \times 3)$ and $(2 \times 4)$ pile groups at $\Delta_{B}=30 \mathrm{~mm}$

experiments on 3 and 4 piles in a row in which the results were approximately the same. Regarding pile displacement, Fig. 12c indicates that increasing the number of piles leads to decrease the lateral displacement of pile group.

The effect of changing the number of pile rows in a direction perpendicular to the direction of soil movement is illustrated in Fig. 13. It can be seen that bending moments values in the front pile row decrease as the number of rows increases. Furthermore, bending moment profiles tend to shift to negative values especially at the middle portion of the pile. The most likely reason for this response is the load sharing process which occurred between the adjacent piles due to the fixity provided by the pile cap. Maximum bending moment calculated at the head of back pile row showed slight changes as pile group configuration changes. On the other hand, bending moments obtained in the stable layer were decreased with increasing the number of pile rows. The maximum bending moment values in the 3 rd pile row of $(4 \times 2)$ pile group was $170 \%$ and $40 \%$ higher as compared to those obtained in the 2 nd pile row of $(4 \times 2)$ and $(3 \times 2)$ pile groups respectively (Fig. 13c). Figure $13 \mathrm{~d}$ reveals that increasing the number of pile rows from 2 to 4 has caused a significant reduction in 


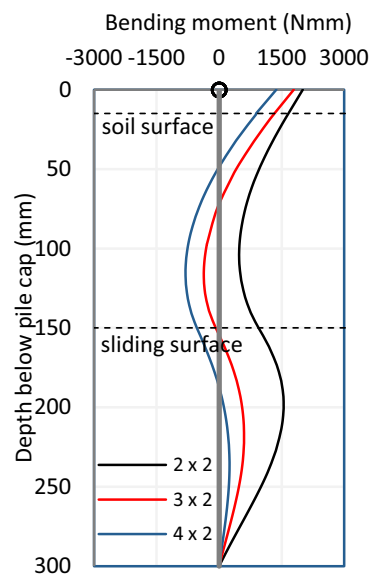

a. Bending moment, pile $\mathrm{F}$

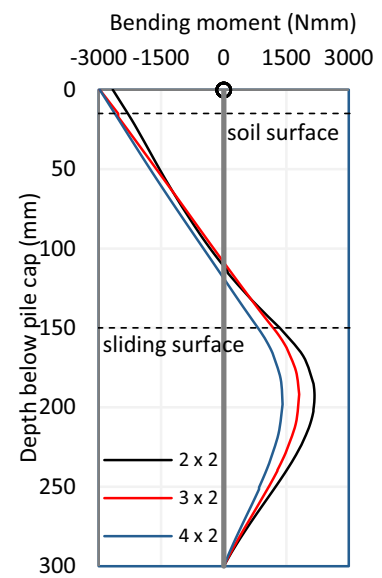

b. Bending moment, pile B

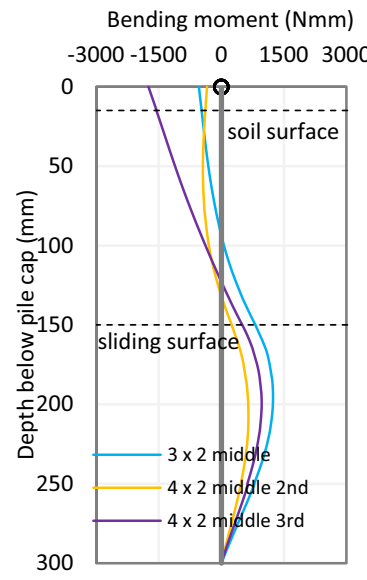

c. Bending moment of interior piles

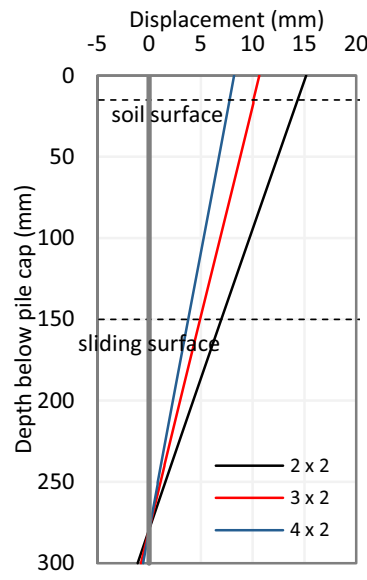

d. Deflection, pile B

Fig. 13 Responses of $(2 \times 2),(3 \times 2)$ and $(4 \times 2)$ pile groups at $\Delta_{B}=30 \mathrm{~mm}$

pile group lateral deflection by about $45 \%$. In general, the predicted response reflects the importance of pile arrangement and the number of piles in the behaviour of passively loaded pile groups especially when the number of rows perpendicular to the direction of soil movement changes.

\section{Conclusions}

Three-dimensional analysis was carried out to back analyse the model tests data of pile groups subjected to lateral soil movements. An elastic-perfectly plastic Mohr-Coulomb model was used to describe the sand behaviour. The pile was modelled using "embedded pile" approach. The back analysis has been conducted on two model tests including uniform and triangular soil movement profiles. The analytical results, generally, confirm a reasonable validation of the software. The general trend of the three predicted profiles deduced analytically (bending moment, shear force and lateral deflection) of piles were in good agreement with those obtained experimentally. However, the comparison between experimental and predicted results revealed some differences in response. The differences were more pronounced when comparing the lateral deformations of piles in which an overestimation of the predicted results was obtained. A number of limitations might be the reason behind these differences. Software limitations and suggestions to improve the current PLAXIS software can be drawn below:

- The first limitation is related to the pile-soil interaction in the lateral direction. The "embedded pile" does not take into account the relative displacement occurred between the soil and piles in the lateral direction. This makes the simulation of "smooth" passive piles, in which the relative pile-soil displacement is a key parameter, not a favorable choice especially when pile displacement is required. Therefore, the prediction of PLAXIS could be improved by incorporating lateral pile-soil interaction to the embedded pile.

- The change in sand density after the instillation of pile group is not taken into account and cannot be simulated with the option of embedded pile. A procedure to consider the effect of pile installation method should be developed to improve embedded pile properties.

In addition to the above limitations, it is found that a number of experimental observations and measurements must be considered for a realistic back analysis of soil movement problems. For this reason, a test without piles was carried out to obtain soil movement profiles at three sections within the testing box. The results and observations of this test were considered as a reference to choose a proper value of the soil strength reduction factor at the sliding layer. 
On the other hand, parametric studies revealed that lateral displacement values showed an increase trend with reducing the value of pile diameter. Furthermore, comparing the behaviour of rigid and flexible piles confirms the importance of the relative pile-soil stiffness factor in determining the response and the deformation mode of both pile types. Also, pile configuration and the position of a pile within the group play an important role in the performance of passive piles, especially when the number of rows perpendicular to the direction of soil movement changes. On the other hand, increasing the number of pile lines parallel to the direction of soil movement beyond 3 lines have showed only a slight difference in the response of piles in terms of deflection and bending moments.

Acknowledgements The authors wish to express their grateful thanks to the Iraqi Ministry of Higher Education and Scientific Research for their support.

Open Access This article is distributed under the terms of the Creative Commons Attribution 4.0 International License (http:// creativecommons.org/licenses/by/4.0/), which permits unrestricted use, distribution, and reproduction in any medium, provided you give appropriate credit to the original author(s) and the source, provide a link to the Creative Commons license, and indicate if changes were made.

\section{References}

Al-abboodi I, Sabbagh TT (2017) Model tests on piled raft subjected to lateral soil movement. Int J Geotech Eng. https://doi.org/10.1080/19386362.2017.1296061

Brinkgreve RBJ, Engin E, Swolfs WM (2010) PLAXIS 3D material models manual. Plaxis company, Delft

Chaudhuri D (2005) Pile foundation response to lateral ground movement. In: Proceedings of (GSP 132) Congress. GeoFrontiers Congress, Texas

Chen LT, Poulos HG, Hull TS (1997) Model tests on pile groups subjected to lateral soil movement. Soils Found 37(1):1-12

Dao TPT (2011) Validation of PLAXIS embedded piles for lateral loading. Dissertation, Delft University

De Beer EE, Wallays M (1972) Forces induced in piles by unsymmetrical surcharges on the soil around the piles. In: Proceedings of the 5th European conference on soil mechanics and foundations engineering. Madrid

Ekici A, Huvaj N (2014) Validation of 3D finite element solution for laterally loaded passive piles. In: Proceedings of NUMGE 2014, the 8th European conference on numerical methods in geotechnical engineering. Delft
Ellis EA, Springman SM (2001) Modeling of soil-structure interaction for a piled bridge abutment in plane strain FEM analyses. Comput Geotech 28(2):79-98

Feng Y, Feng C, Fa-Yun L (2010) A preliminary study on the behavior of axially loaded single pile subjected to lateral soil movement behind a retaining wall. In: Proceedings of GeoShanghai international conference on deep and underground excavations (GSP 206), geotechnical special publication, ASCE, pp 76-83

Galli A, di Prisco C (2012) Displacement-based design procedure for slope-stabilizing piles. Can Geotech J 50(1):41-53

Ghee H, Guo WD (2011) FLAC3D analysis on soil moving through piles. In: Proceedings of the 2 nd international symposium on frontiers in offshore geotechnics. Perth

Haryono IS (2013) Pile foundation and soil response to deep excavation. Dissertation, Delft University

He Y, Hazarika H, Yasufuku N, Han Z (2015) Evaluating the effect of slope angle on the distribution of the soil-pile pressure acting on stabilizing piles in sandy slopes. Comput Geotech 69:153-165

Hirai H (2016) Analysis of piles subjected to lateral soil movements using a three-dimensional displacement approach. Int $\mathbf{J}$ Numer Anal Methods Geomech 40:235-268

Ito T, Matsui T (1975) Methods to estimate lateral force acting on stabilizing piles. Soils Found 15(4):43-60

Jeong S, Kim B, Won J, Lee J (2003) Uncoupled analysis of stabilizing piles in weathered slopes. Comput Geotech 30(8):671-682

Kahyaoglu MR, Imancli G, Ozturk AU, Kayalar AS (2009) Computational 3D finite element analyses of model passive piles. Comput Mater Sci 46:193-202

Kanagasabai S (2010) Three dimensional numerical modelling of rows of discrete piles used to stabilise large landslides. Dissertation, University of Southampton

Kok ST, Huat BBK (2008) Numerical modeling of laterally loaded piles. Am J Appl Sci 5(10):1403-1408

Kourkoulis R, Gelagoti F, Anastasopoulos I, Gazetas G (2011) Slope stabilizing piles and pile-groups: parametric study and design insights. J Geotech Geoenviron Eng 137(7):663-678

Lee CY, Hull TS, Poulos HG (1995) Simplified pile-slope stability analysis. Comput Geotech 17(1):1-14

Li L, Dong G, Zhang F, Yang M (2014) Three-dimensional numerical analyses of pile response due to unstrutted excavation-induced lateral soil movement. In: Proceedings of the 3rd GeoShanghai international conference. Shanghai

Madhumathi RK, Ilamparuthi K (2018) Laboratory study on response of single pile adjacent to supported cut. Geotech Geol Eng 36:3111. https://doi.org/10.1007/s10706-0180524-9

Martin G, Chen C (2005) Response of piles due to lateral slope movement. Comput Geotech 83(8-9):588-598

Miao LF, Goh ATC, Wong KS, Teh CI (2006) Three-dimensional finite element analyses of passive pile behaviour. Int J Numer Anal Methods Geomech 30(7):599-613

Ng CWW, Zhang LM (2001) Three-dimensional analysis of performance of laterally loaded sleeved piles in sloping ground. J Geotech Geoenviron Eng 127(6):499-509 
Nguyen HH, Khabbaz H, Fatahi B, Kelly R (2016) Bridge pile response to lateral soil movement induced by installation of controlled modulus columns. Proc Eng 143:475-482

Nishanthan R, Liyanapathirana DS, Leo CJ (2017) Shielding effect in pile groups adjacent to deep unbraced and braced excavations. Int J Geotech Eng 11(2):162-174. https://doi. org/10.1080/19386362.2016.1200270

Pan JL, Goh ATC, Wong KS, Teh CI (2002) Ultimate soil pressures for piles subjected to lateral soil movements. J Geotech Geoenviron Eng 128(6):530-535

Poulos HG (1973) Analysis of piles in soil undergoing lateral movement. J Soil Mech Found Eng Div 99:391-406

Poulos HG (1989) Pile behaviour-theory and application. Geotechnique 39(3):365-415

Poulos HG, Davis EH (1980) Pile foundation analysis and design. Wiley, New York

Sawant VA, Shukla SK (2012) Finite element analysis for laterally loaded piles in sloping ground. Coupled Syst Mech 1(1):59-78
Sheil BB, Mccabe BA (2012) Predictions of friction pile group response using embedded piles in PLAXIS. In: Proceedings of the 3rd international conference on new developments in soil mechanics and geotechnical engineering. Nicosia

Sluis J, Besseling F, Stuurwold P, Lengkeek A (2013) Validation and application of the embedded pile row-feature in PLAXIS 2D. Plaxis Bull 34:10-13

Viggiani C (1981) Ultimate lateral load on piles used to stabilized landslides. In: Proceedings of 10th international conference on soil mechanics and foundation engineering. Stockholm, pp 555-560

Wang Z, Zhang Y, Yang C, Li X (2013) Load-bearing arching between cantilever piles and influencing factors. Electron J Geotech Eng 18(2013):6163-6172

Publisher's Note Springer Nature remains neutral with regard to jurisdictional claims in published maps and institutional affiliations. 